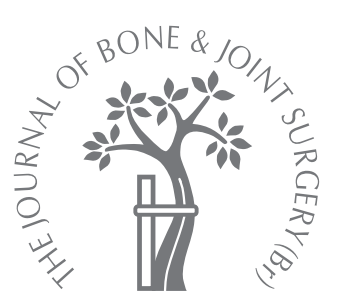

B. Derbyshire, M. L. Porter

From Wrightington Hospital, Appley Bridge, England

\title{
A study of the Elite Plus femoral component using radiostereometric analysis
}

We performed a three-year radiostereometric analysis (RSA) study of the Elite Plus femoral component on 25 patients undergoing primary total hip replacement. Additional assessments and measurements from standard radiographs were also made.

Subsidence of the stem occurred at the cement-stem interface. At 36 months the subsidence of the stem centroid was a mean of $0.30 \mathrm{~mm}(0.02$ to 1.28$)$, and was continuing at a slow rate. At the same time point, internal rotation and posterior migration of the femoral head had ceased. One stem migrated excessively and additional assessments suggested that this was probably due to high patient demand.

The failure rate of $4 \%$ in our study is consistent with data from arthroplasty registers but contrasts with poor results from another RSA study, and from some clinical studies. We believe that the surgical technique, particularly the use of high-viscosity cement, may have been an important factor contributing to our results.

The Elite Plus system (DePuy International Ltd, Leeds, United Kingdom) was the latest "evolution" of the successful Charnley lowfriction arthroplasty (DePuy). Following the modular Elite version, the Elite Plus stem was designed to improve load transfer to the proximal femur. ${ }^{1}$ Like the Charnley, it is 'shapeclosed'2 with a proximal flange, single taper and a textured surface. A distal centraliser is included to improve cement mantle uniformity.

Published reports on the medium-term performance of the Elite Plus stem have been conflicting, with some recording an unsatisfactory ${ }^{3-6}$ and others a good outcome. ${ }^{7-9}$

Using radiostereometric analysis (RSA), it has been shown that shape-closed femoral components migrate very little during the first few years and that any excessive departure from this general trend signals loosening and failure in the medium- to long-term. ${ }^{10}$ Radiostereometric analysis is therefore a useful short-term tool for predicting the failure of prostheses.

We report the results of an RSA study of the Elite Plus stem and compare them with those of other RSA and clinical studies of this implant.

\section{Patients and Methods}

Elite Plus femoral components were modified for RSA by the manufacturer (DePuy) with tantalum marker beads at the stem shoulders and tips. Following ethical approval and informed consent, 29 patients underwent primary total hip replacement (THR) using the beaded stems and Charnley flanged acetabular components (DePuy). Four patients were subsequently excluded because they had an insufficient number or scatter of visible bone marker beads, leaving 25 in the study. Additional details of the patients are given in Table I. There were 17 women and eight men, and the diagnosis was osteoarthritis in 23 patients and rheumatoid arthritis in two. The mean age of the patients was 60.4 years (37 to 81 ). A total of 17 implants were on the left side. One patient had a bilateral THR (one RSA stem on the right side).

The operations were carried out by one surgeon (MLP) between February 2000 and April 2001. A posterior surgical approach was used in three patients and a lateral (Hardinge ${ }^{11}$ ) approach in the others. Fourth-generation cementing techniques were used including distal femoral occlusion, pulsatile lavage, the use of high-viscosity cement, proximal femoral occlusion and cement pressurisation for up to five minutes before insertion of the stem. Up to eight tantalum marker beads were injected into the cancellous bone of the proximal femur immediately before the introduction of the cement. A marker bead in seven of the plastic cement restrictors allowed migration of the cement mantle to be followed. Stem centralis- 
Table I. Details of the 25 patients

\begin{tabular}{lcl}
\hline & \multicolumn{2}{c}{ Mean } \\
\hline Age $(\mathrm{yrs})$ & 60.4 & $(37$ to $81 ; 13.7)$ \\
Weight $(\mathrm{kg})$ & 78.1 & $(44.5$ to $99.9 ; 15.1)$ \\
Height $(\mathrm{m})$ & 1.67 & $(1.52$ to $1.84 ; 0.09)$ \\
Body mass index $\left(\mathrm{kg} / \mathrm{m}^{2}\right)$ & 28.1 & $(17.8$ to $36.9 ; 4.62)$ \\
Effective offset $(\mathrm{mm})$ & 38.3 & $(35.4$ to $40 ; 1.58)$ \\
\hline
\end{tabular}

ers were used on 15 femoral components. There were 15 size- 3 and ten size- 2 stems, all of which were flanged with standard offset. All the femoral heads were $22.23 \mathrm{~mm}$ in diameter (14 zirconia, 11 stainless steel). The acetabular components were fixed by using CMW2 cement (DePuy CMW, Blackpool, United Kingdom).

Radiostereometric analysis. Radiostereometric analysis (UmRSA; RSA BioMedical, Umea, Sweden) examinations were undertaken at approximately seven days (used as a reference) and at $1,3,6,12,24$ and 36 months. One patient (case 16) missed the seven-day and one-month examinations, so it was decided to continue her subsequent examinations using the three-month examination as the reference, but setting this value at the mean of the other stem segment migrations at that time (thereby keeping the overall mean values at three months the same). Only stem segment migrations were recorded for this patient. The analysis and statistics were carried out on two sets of stem segment results, with and without the inclusion of case 16. Migrations of individual landmarks (head, shoulder, tip) were not followed for this patient and therefore the overall analysis and statistics of individual points were for 24 patients.

The repeatability, assuming negligibly small bias error, ${ }^{12}$ of the RSA technique was estimated by carrying out 'double examinations'. To minimise the risks of exposure to radiation, only five patients were measured because they had received the least overall exposure, i.e. not as many repeat sessions for inadequate radiographs. For each double examination, the patient was removed and the radiological equipment repositioned between examinations. The repeatability was determined according to Ranstam, et a ${ }^{12}$ except that, instead of using a repeatability coefficient of 1.96 , we used Student's $t$-value for the small sample of five (repeatability $= \pm t \times \mathrm{SD}$, where $\mathrm{n}$ instead of $\mathrm{n}-1$ was used as the denominator of the SD). The repeatability coefficient was half of the range of values within which $95 \%$ of the differences between the double examinations were expected to lie.

Patient scores and measurements. At 36 months the Charnley modification ${ }^{13}$ of the Merle d'Aubigné and Postel hip score ${ }^{14}$ was recorded.

In an attempt to assess activity, the patients were asked to choose a score as follows: 1) low activity (mainly chairbound or modest daily movement); 2 ) average activity (general housework, shopping, some walking required at work); 3) above average activity (manual worker required to stand/walk regularly, or regularly partakes in energetic exercise such as walking at weekends or modest sport); 4) highly active (job requires heavy manual labour, standing for several hours per day) or partakes in sporting activity.

Measurement and grading of standard radiographs. Cementing quality was assessed from standard anteroposterior (AP) radiographs and the scoring system of Barrack, Mulroy and Harris ${ }^{15}$ agreed upon by two observers (BD and another, who was not an author). Radiolucent zones were recorded according to the system of Gruen, McNiece and Amstutz. ${ }^{16}$

Additional measurements were taken from AP and lateral radiographs using CAD software, ${ }^{17}$ and correlation with the migrations/rates were assessed. In total, $23 \mathrm{AP}$ and 16 lateral radiographs were suitable for these measurements.

Statistical analysis. StatsDirect statistical software ${ }^{18}$ was used for all statistical calculations. The Shapiro-Wilk test ${ }^{19}$ was used for evidence of non-normality. Student's $t$-test, paired when appropriate, was used for significance tests and a value of $\mathrm{p} \leq 0.05$ was considered to be statistically significant. The confidence intervals (CIs) presented are at the $95 \%$ level.

\section{Results}

Precision of measurement. The repeatability of the measurements from the double examinations is shown in Table II. Repeatability in the X-Y (coronal) plane was high, especially for the stem segment as a whole but, as expected, the out-of-plane (Z) repeatability was not as good. The deterioration in repeatability with increasing distance from the bone markers (reference segment) in the proximal femur was also expected, hence the worse measurements

Table II. Measurement precision from double examinations of five patients. The translations are along and the rotations about the lateral $(\mathrm{X})$, proximal $(\mathrm{Y})$ and anterior $(Z)$ axes. Resultant translation $=\sqrt{ } X^{2}+Y^{2}+Z^{2}$

\begin{tabular}{lllll}
\hline & \multicolumn{2}{l}{ Axis } & & \\
\cline { 2 - 4 } & $\mathbf{X}$ & $\mathbf{Y}$ & $\mathbf{Z}$ & Resultant \\
\hline Stem centroid translation $(\mathrm{mm})$ & 0.08 & 0.06 & 0.13 & 0.16 \\
Stem rotation ( ${ }^{\circ}$ ) & 0.28 & 0.75 & 0.12 & \\
Head translation (mm) & 0.12 & 0.07 & 0.37 & 0.4 \\
Shoulder translation (mm) & 0.15 & 0.09 & 0.28 & 0.33 \\
Tip translation (mm) & 0.19 & 0.16 & 0.46 & 0.53 \\
\hline
\end{tabular}




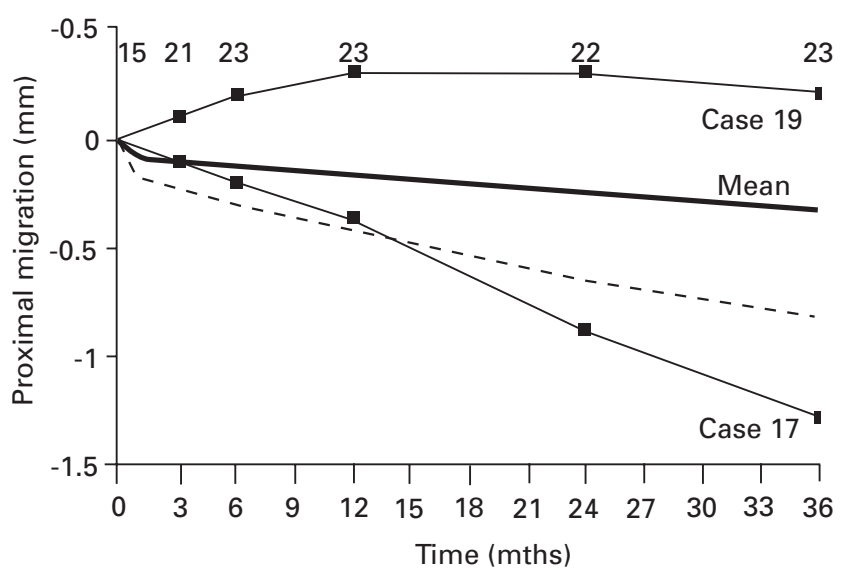

Fig. 1

Graph showing the proximodistal migration of the femoral component centroid. The mean (absolute) excludes migrations for cases 16 and 19. The dashed line represents two SDs from the mean absolute value at each of the examination times. The patient count is shown at the top.

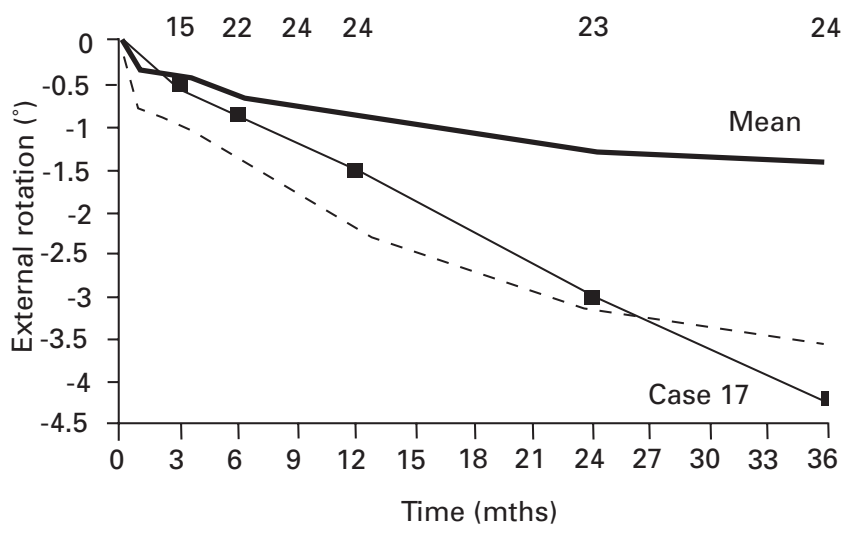

Fig. 2

Graph showing the internal rotation of the femoral component excluding case 16. The dashed line represents two SDS from the mean absolute value at each of the examination times. The patient count is shown at the top.

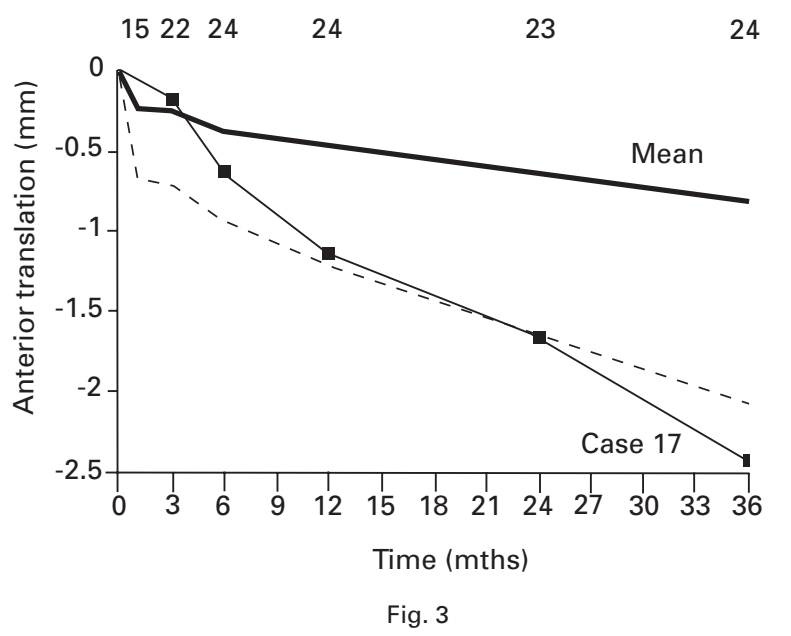

Graph showing the posterior migration of the femoral head. The dashed line represents two SDS from the mean absolute value at each of the examination times. The patient count is shown at the top.

for repeatability of the stem tip. These results compare favourably with those of other studies that have used the UmRSA system.

Migrations. Although some of the data sets failed the Shapiro-Wilk test for normality, a 'boot-strap' analysis of our most skewed data showed very similar 95\% CIs to those of the standard $t$-test. A similar finding was reported by Alfaro-Adrian, Gill and Murray, ${ }^{20}$ who carried out Monte Carlo simulations on their data. Nevertheless, when appropriate, we reinforced our findings by non-parametric statistical analysis.
The femoral component centroid of one patient (case 19) migrated proximally and its proximodistal migration was analysed separately during statistical analysis (Fig. 1). Migration components in other directions were not analysed separately for this patient. The remaining 24 components subsided (Fig. 1). The mean subsidence at 24 months was $0.25 \mathrm{~mm}(0.01$ to 0.88$)$ and by 36 months it was $0.30 \mathrm{~mm}$ (0.02 to 1.28$)$, the changes during this period being statistically significant (paired $t$-test $\mathrm{p}=0.0052,95 \%$ CI 0.018 to 0.089 ). Exclusion of the segment data of case 16 did not alter these values appreciably (24 months, 0.25 $\mathrm{mm} ; 36$ months, $0.31 \mathrm{~mm}$, paired $t$-test $\mathrm{p}=0.009 ; 95 \% \mathrm{CI}$ 0.014 to 0.089 ). These changes remained statistically significant when the proximal migration of case 19 was included in the analysis (and excluding case 16) of the absolute values (paired $t$-test, $\mathrm{p}=0.02 ; 95 \%$ CI 0.008 to 0.083 ; Wilcoxon signed-ranks test, median difference $=0.046 \mathrm{~mm}$, $\mathrm{p}<0.001 ; 95 \%$ CI 0.017 to 0.053 ). If the subsidence of case 17 was excluded from the analysis (excluding case 16 and including case 19), there was still a statistically significant change in subsidence during the last year (paired $t$-test; $\mathrm{p}<0.01$; $95 \%$ CI 0.011 to 0.048 ; Wilcoxon signed-rank test, median difference $=0.028 \mathrm{~mm}, \mathrm{p}<0.001 ; 95 \% \mathrm{CI}$ 0.016 to 0.045$)$.

All the prostheses underwent internal rotation with a mean of $1.3^{\circ}\left(0.1^{\circ}\right.$ to $\left.3.5^{\circ}\right)$ at 24 months and of $1.4^{\circ}\left(0.2^{\circ}\right.$ to $4.2^{\circ}$ ) at 36 months (Fig. 2). However, the changes during the third year were not statistically significant (paired $t$-test, $p=0.1231 ; 95 \%$ CI -0.04 to 0.32 ). The exclusion of the segment data of case 16 did not appreciably affect this (24 months; 36 months, $1.4^{\circ}, 1.3^{\circ}$, paired $t$-test, $\mathrm{p}=0.1951$, $95 \%$ CI -0.07 to 0.30 ).

The mean subsidence of the femoral heads was $0.36 \mathrm{~mm}$ (0.02 to 1.10$)$ at 24 months and $0.40 \mathrm{~mm} \mathrm{(0.02} \mathrm{to} 1.61)$ at 
Table III. Summary of measurements from standard anteroposterior (AP) and lateral radiographs

\begin{tabular}{|c|c|c|}
\hline \multirow[b]{2}{*}{ AP measurements $(n=23)$} & \multicolumn{2}{|c|}{ Mean (range; SD) } \\
\hline & & \\
\hline Femoral canal width at isthmus in $\mathrm{mm}$ & 14.11 & (9.8 to $22.6 ; 3.07)$ \\
\hline Femur width at isthmus in $\mathrm{mm}$ & 26.18 & (21.1 to $29.9 ; 2.23$ ) \\
\hline Cortical index & 0.46 & $(0.17$ to $0.62 ; 0.12)$ \\
\hline Flare index & 3.06 & $(1.75$ to $4.64 ; 0.78)$ \\
\hline Lateral flare index & 2.81 & $(1.20$ to $4.63 ; 0.95)$ \\
\hline Medial flare index & 3.32 & $(2.17$ to $5.39 ; 0.84)$ \\
\hline Stem varus in ${ }^{\circ}(n=18)$ & 2.01 & $(0.00$ to $4.4 ; 1.32)$ \\
\hline Stem valgus in ${ }^{\circ}(n=5)$ & 0.79 & $(0.00$ to $1.7 ; 0.57)$ \\
\hline Stem medial to femoral axis in $\mathrm{mm}(\mathrm{n}=17)$ & 2.49 & $(0.00$ to $5.2 ; 1.76)$ \\
\hline Stem lateral to femoral axis in $\mathrm{mm}(\mathrm{n}=6)$ & 0.98 & $(0.00$ to $1.85 ; 0.68)$ \\
\hline Proximomedial cement thickness in $\mathrm{mm}$ & 6.22 & (2.1 to $11.4 ; 2.22)$ \\
\hline Proximolateral cement thickness in $\mathrm{mm}^{*}$ & 5.19 & $(2.4$ to $11.2 ; 1.87)$ \\
\hline Tip cement thickness, medial in $\mathrm{mm}$ & 4.2 & $(1.2$ to $8.4 ; 1.91)$ \\
\hline Tip cement thickness, lateral in $\mathrm{mm}$ & 3.29 & (0.8 to $6.1 ; 1.34)$ \\
\hline \multicolumn{3}{|l|}{ Lateral measurements $(n=16)$} \\
\hline Femoral canal width at isthmus in $\mathrm{mm}$ & 18.14 & (14.3 to $24.3 ; 3.32)$ \\
\hline Femur width at isthmus in $\mathrm{mm}$ & 28.81 & (22.7 to $34.7 ; 3.34)$ \\
\hline Cortical index & 0.36 & $(0.07$ to $0.54 ; 0.14)$ \\
\hline Stem flexion (tip anterior) in ${ }^{\circ}(n=1)$ & 0.59 & \\
\hline Stem extension (tip posterior) in ${ }^{\circ}(n=15)$ & 4.1 & $(0.00$ to $9.1 ; 2.19)$ \\
\hline Stem to femoral axis in $\mathrm{mm}(\mathrm{n}=16)$ & 3.58 & $(0.4$ to $8.5 ; 2.16)$ \\
\hline Proximoanterior cement thickness in $\mathrm{mm}$ & 3.85 & (1.20 to $8.03 ; 1.63)$ \\
\hline Proximoposterior cement thickness in $\mathrm{mm}$ & 9.94 & (4.7 to $14.8 ; 2.93$ ) \\
\hline Tip cement thickness, anterior in $\mathrm{mm}^{\dagger}$ & 6.97 & (4.6 to $12.2 ; 2.26)$ \\
\hline Tip cement thickness, posterior in $\mathrm{mm}^{\ddagger}$ & 3.72 & (1.10 to $9.40 ; 2.13)$ \\
\hline \multicolumn{3}{|c|}{$\begin{array}{l}\text { Up to two values caused the distribution to be non-normal in these cases } \\
\text { * median, } 4.8 \mathrm{~mm} \\
\text { † median, } 6.5 \mathrm{~mm} \\
\text { † median, } 3.5 \mathrm{~mm}\end{array}$} \\
\hline
\end{tabular}

36 months. The changes in subsidence were not statistically significant (paired $t$-test, $\mathrm{p}=0.0704 ; 95 \%$ CI -0.004 to $+0.099)$. At 36 months, all the femoral heads had migrated posteriorly by a mean of $0.80 \mathrm{~mm}(0.02$ to 2.43$)$ (Fig. 3), but the migration differences compared with the measurements at 24 months were not significant (paired $t$-test, $\mathrm{p}=0.1019 ; 95 \%$ CI -0.25 to +0.02$)$. Similarly, migration of the femoral head in the transverse plane (mean $0.76 \mathrm{~mm}$ (0.11 to 2.26$)$ at 24 months and $0.90 \mathrm{~mm} \mathrm{(0.09}$ to 3.09$)$ at 36 months) showed no statistically significant changes during that year (paired $t$-test, $\mathrm{p}=0.062,95 \%$ CI -0.026 to $+0.01)$.

The femoral components of two patients (cases 17 and 19) showed unusual migration. In case 19 , the femoral component centroid migrated $0.32 \mathrm{~mm}$ proximally during the first 12 months (Fig. 1). The accompanying proximolateral migration of the femoral head, proximomedial migration of the stem tip and lateral migration of the stem shoulder described stem valgus rotation $\left(0.9^{\circ}\right.$ at 12 months, then stabilising) about an axis close to the shoulder.

A threshold of two SDs from the mean absolute value was used to signal abnormally high migration. If migration of a stem is more than two SDs from the mean, it can be cautiously predicted that it no longer belongs to the main population of migrations and is tending to be an outlier.
Beyond three SDs it is more likely to be an outlier. In case 17 , subsidence and medial migration of the centroid, femoral head and shoulder of the stem, as well as varus rotation, had either breached or were close to three SDs from the mean absolute values by 24 months (Fig. 1). Internal rotation and posterior translation of the femoral head were then around two SDs from the mean absolute value (Figs 2 and 3). The patient's acetabular component had completely demarcated at the cement-bone interface, shown by a radiolucent line on the AP radiograph, from approximately 12 months post-operatively, but a leucoscan was negative and inflammatory markers were normal. The period of RSA examinations was extended for this patient. At 56 months (36 months), centroid subsidence, internal rotation and femoral head posterior migrations were $1.63 \mathrm{~mm}$ $(1.28 \mathrm{~mm}), 4.1^{\circ}\left(4.2^{\circ}\right)$ and $2.33 \mathrm{~mm}(2.43 \mathrm{~mm})$, respectively. In addition, this patient had a high activity score of 4 . This was corroborated by a radiological wear measurement of $3.5 \mathrm{~mm}$ (three times the expected rate), of the contralateral Charnley hip at nine years after operation. It had been revised at 12 years.

Migration of the cement mantle. Proximodistal migration of five cement restrictor markers was within measurement repeatability error (stem tip Y-direction repeatability $0.16 \mathrm{~mm}$, Table II). The subsidence of another restrictor 
marker was higher than this, reaching $0.14 \mathrm{~mm}$ at three months and rising slowly to $0.19 \mathrm{~mm}$ at 36 months. This measurement was probably also a reflection of measurement error because the restrictor marker was more than 20 $\mathrm{mm}$ distal to the tip of the stem. Hence, measurement repeatability would probably have been worse than that recorded for the tip of the stem because it was further from the reference markers in the proximal femur. The cement restrictor marker in case 19 migrated proximally to 0.28 mm during the first 12 months and barely moved thereafter. This was similar to the proximal migration of the stem centroid $(0.32 \mathrm{~mm})$.

Grades and scores. Post-operative Barrack et $\mathrm{al}^{15}$ cementing grades were: four grade A, 16 grade $B$ and five grade C. Affected Gruen zones were: 13 zone 2, 18 zone 3, nine zone 5 , eight zone 6 and one zone 7 . Case 17 had a grade $B$ cement score, and cement deficiencies and their distribution were noted in Gruen zones 2 and 3. The mean Charnley modification of the Merle d'Aubigné and Postel hip score ${ }^{13}$ at 36 months for pain, movement and walking were 5.55 (1 to 6 ), 4.95 (3 to 6 ), and 5.27 (2 to 6), respectively. For the activity scores there were six patients with score 1,11 with score 2, seven with score 3, and one with 4 .

Measurements from standard radiographs. A summary of the standard radiological measurements is shown in Table III. From the AP radiographs, there were 13 'stovepipe' femora and ten of normal shape. ${ }^{21}$ The mean medial flare index was larger than the mean lateral index but the difference was not statistically significant $(t$-test, $\mathrm{p}=$ $0.0592,95 \%$ CI 0.02 to +1.05$)$. In the AP view, the cement thickness at the tip of the stem was less than $2 \mathrm{~mm}$ in seven patients (three medially, four laterally), but only one of those $(0.8 \mathrm{~mm})$ was less than $1 \mathrm{~mm}$. In the lateral view, one patient had a proximal cement thickness of less than $2 \mathrm{~mm}$ and three at the tip of the stem were less than $2 \mathrm{~mm}$, with none less than $1 \mathrm{~mm}$. A total of 18 stems were in varus orientation and five were in valgus. At the level of the most medial point of the lesser trochanter, the stem centreline was medial to the femoral axis in 17 cases and lateral to it in six. In case 17 , the stem was orientated at $1.7^{\circ}$ valgus, the stem centreline was $1.85 \mathrm{~mm}$ lateral to the femoral axis at the level of the lesser trochanter, and the cement thickness was not less than $2 \mathrm{~mm}$.

\section{Discussion}

Huiskes et $\mathrm{al}^{2}$ described the two different approaches to cemented femoral stem design in a translation from German engineering terms: shape-closed and force-closed. We believe that these design approaches are perhaps more suitably described by the words 'contained' and 'constrained'. Huiskes et $\mathrm{al}^{2}$ emphasised that the two design approaches were simply convenient categorisations and that the difference between them was not always clear cut. Thus, a contained stem, such as the Elite Plus, does subside and migrate - at least during the first few months - but the magnitude of subsidence should be relatively small compared with that of a constrained stem. Overall, this is what we found in the present study. A mean subsidence at 36 months of $0.3 \mathrm{~mm}$ is four to five times less than what might be expected of a constrained type of component..$^{20,22,23}$ However, subsidence was still continuing at 36 months, albeit at a slow rate. Slow continuous subsidence over several years is still consistent with success. ${ }^{10}$ It is continuous and relatively rapid migration which does not auger well for contained femoral stems. ${ }^{10}$ Judging from migrations of the small number of cement restrictor markers that we followed, stem subsidence would appear to have occurred within the cement mantle; the mantle itself having no measurable subsidence relative to the proximal femur. By 36 months, the other main components of migration (internal rotation and posterior femoral head migration) had ceased, showing no statistically significant changes during the third year. Our data compares favourably with the centroid migration results of Grant et $\mathrm{al}^{24}$ whose study lasted for 24 months.

Excessive migration occurred in one femoral component (case 17 , Figs 1 to 3 ) and the patient's high activity score and excessively worn contralateral acetabular component suggested that high demand was a major cause. The continuing high subsidence rate at nearly five years is a cause for concern and possibly indicates a need for future revision. Our study therefore showed a rate of failure of $4 \%$ for the Elite Plus design, but it is possible that any design of stem would have been a candidate for failure in this highdemand patient. This rate is consistent with survival rates in arthroplasty registers. ${ }^{25,26}$ With aseptic loosening as the end-point, the survival rate at nine years in the Danish Register $^{25}$ was $100 \%$ with the Charnley Ogee component (DePuy) and $98.1 \%$ with the standard Charnley acetabular component (DePuy). In the Swedish Register ${ }^{26}$ it was 98.5\% with the standard Charnley acetabular components (DePuy) at five years.

The proximal migration of the femoral component in case 19 was due to valgus rotation about the shoulder of the stem and we cannot explain this. The other stems, as might be expected, rotated into varus. Others who have reported proximal migration of the femoral component centroid $^{27}$ and femoral head ${ }^{27,28}$ considered it to be a good prognostic sign. ${ }^{27}$ In our case, migration levelled off after 12 months and we consider this unusual early pattern of migration to be of no clinical significance.

Some aspects of our study may have biased the results in a favourable direction. First, the THRs were undertaken by one surgeon at a specialist centre. Secondly, he had implanted 314 Elite Plus stems during the five years before the RSA study. Thirdly, only stems of size 2 and 3 were implanted and none had a high offset. Nevertheless, they were of average size, the quality of cementing technique was average and the cement mantle was deficient in seven patients.

The encouraging results of the present study are in stark contrast to those from an RSA study by Alfaro-Adrian et $\mathrm{al}^{20}$ who predicted that four of 19 femoral components 
would fail (recently confirmed ${ }^{6}$ ) because of excessive posterior head migration. It might seem from these conflicting studies, therefore, that the validity of RSA as a screening technique for new stems has been challenged. However, it is important to realise that RSA is not a diagnostic tool; it does not tell us why excessive migration has occurred. This is why two RSA studies of the same type of prosthesis can have completely different results. In our study, numerous measurements and assessments were taken for each patient to assist the explanation of any excessive migration. ${ }^{29}$ The necessity of additional assessments is exemplified by the findings for the single potential failure in our study. An RSA study showing excessive migration, and which does not include sufficient additional assessments, is likely to result in a condemnation of the prosthesis.

There have also been conflicting clinical studies of the Elite Plus stem. ${ }^{3-9}$ We believe that it is likely that the surgical technique contributed to some poor results. A common factor linking poor results in clinical and RSA studies is the use of low-viscosity cement, which has been associated with an increased rate of failure of the Charnley low-friction arthroplasty. ${ }^{30-32}$ In Norway and Sweden, cements such as Sulfix and CMW3 are no longer used. ${ }^{31}$ The Oxford group has recently reported it used low-viscosity cement without proximal seals in $\mathrm{RSA}^{20}$ and also in clinical studies. ${ }^{6}$

\section{Supplementary Material}

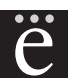
A further opinion by Professor D. Rowley is available with the electronic version of this article on our website at www.jbjs.org.uk

We would like to thank Elaine Broxholme, Senior Radiographer, who carried out most of the RSA and advised on radiological issues. We thank Louise Bale, Research Nurse, for her assistance with grading cement mantles. Dr C. Sutton, Lancashire School of Health and Postgraduate Medicine, University of Central Lancashire, and Professor R. Prescott, Department of Public Health Science, University of Edinburgh, provided statistical advice.

The author or one or more of the authors have received or will receive benefits for personal or professional use from a commercial party related directly or indirectly to the subject of this article. In addition, benefits have been or will be directed to a research fund, foundation, educational institution, or other nonprofit organisation with which one or more of the authors are associated.

\section{References}

1. DePuy International Ltd. Charnley Elite Plus Handbook. Cat. No. 9065-94.

2. Huiskes R, Verdonschot N, Nivbrant B. Migration, stem shape, and surface finish in cemented total hip arthroplasty. Clin Orthop 1998;355:103-12.

3. Livingston SJ, Ivory JP. Five year survivorship study of the Charnley Elite Plus total hip replacement. J Bone Joint Surg [Br] 2003;85-B(Suppl 1):59-60.

4. Walton NP, Darrah C, Shepstone L, Donell ST, Phillips H. The Elite Plus arthroplasty: the need for radiological surveillance. J Bone Joint Surg [Br]2005;87-B:458-62.

5. Rowsell M, Der Tavitian J, Birtwistle S, Power R. Survivorship of the Charnley Elite Plus cemented femoral stem. Int Orthop 2005:29:214-18.
6. Hauptfleisch J, Glyn-Jones S, Beard DJ, Gill HS, Murray DW. The premature failure of the Charnley Elite Plus stem. J Bone Joint Surg [Br] 2006;88-B:179-83.

7. Kalairajah Y, Azurza K, Molloy A, et al. Is the Charnley evolution working?: a 5 year outcome study. Acta Orthop Belg 2004;70:315-21.

8. Brokelman RBG, van Loon CJM, Rijnberg WJ. Patient versus surgeon satisfaction after total hip arthroplasty. J Bone Joint Surg [Br]2003;85-B:495-8.

9. Kim Yh, Kim JS, Yoon SH. Long-term survivorship of the Charnley Elite Plus femoral component in young patients. J Bone Joint Surg [Br] 2007;89-B:449-54.

10. Karrholm J, Borssen B, Lownhielm G, Snorrason F Does early micromotion of femoral stem prostheses matter?: 4-7 year stereoradiographic follow-up of 84 cemented prostheses. J Bone Joint Surg [Br] 1994;76-B:912-17.

11. Hardinge K. The direct lateral approach to the hip. J Bone Joint Surg [Br] 1982; 64B:17-19

12. Ranstam J, Ryd L, Onsten I. Accurate accuracy assessment. Acta Orthop Scand 2000;71:106-8.

13. Charnley J. The long term results of low-friction arthroplasty of the hip performed as a primary intervention. J Bone Joint Surg [Br] 1972;54-B:61-76.

14. D'Aubigne RM, Postel M. Functional results of hip arthroplasty with acrylic prosthesis. J Bone Joint Surg [Am] 1954;36-A:451-75.

15. Barrack RL, Mulroy RD, Harris WH. Improved cementing technique and femoral component loosening in young patients with hip arthroplasty. J Bone Joint Surg [Br] 1992;74-B:385-9

16. Gruen TA, McNiece GM, Amstutz HC. Modes of failure of cemented stem-type femoral components: a radiographic analysis of loosening. Clin Orthop 1979;141:1727

17. No authors listed. Design CAD. http://www.designcad.com/ (date last accessed 31 May 2007).

18. No authors listed. Statsdirect. http://statsdirect.com/ (date last accessed 31 May 2007).

19. Shapiro SS, Wilk MB. Analysis of variance test for normality (complete samples). Biometrica 1965;52:591-611.

20. Alfaro-Adrian J, Gill HS, Murray DW. Should total hip arthroplasty femoral components be designed to subside? J Arthroplasty 2001;16:598-606.

21. Noble PC, Alexander JW, LindahI LJ, et al. The anatomic basis of femoral component design. Clin Orthop 1988;235:148-65

22. Stefansdottir A, Franzen H, Johnsson R, Ornstein E, Sundberg M. Movement pattern of the Exeter femoral stem. Acta Orthop Scand 2004;75:408-14.

23. Sundberg M, Besjakov J, Von Schewelow T, Carlsonn A. Movement patterns of the C-stem femoral component. J Bone Joint Surg [Br] 2005;87-B:1352-6.

24. Grant P, Aamodt A, Falch JA, Nordsletten L. Differences in stability and bone remodelling between a customised uncemented hydroxyapatite coated and a standard cemented femoral stem. J Orthop Res 2005;23:1280-5.

25. No authors listed. Danish arthroplasty register. Annual report 2005. http:// www.dhr.dk/ENGLISH.htm (date last accessed 31 May 2007).

26. No authors listed. Swedish arthroplasty register. Annual report 2004. http:// www.jru.orthop.gu.se/ (date last accessed 31 May 2007).

27. Karrholm J, Malchau J, Snorrason F, Herberts P. Micromotion of femoral stems in total hip arthroplasty. J Bone Joint Surg [Am] 1994;76-A:1692-705.

28. Onsten I, Akesson K, Besjakov J, Obrant KJ. Migration of the Charnley stem in rheumatoid arthritis and osteoarthritis. J Bone Joint Surg [Br] 1995;77-B:18-22.

29. Porter ML, Derbyshire B. RSA study comparing migration of Charnley Elite and Exeter hip stems. J Arthroplasty 2003;18:121.

30. Havelin LI, Espehaug B, Vollset SE, Engesaeter LB. The effect of the type of cement on early revision of Charnley total hip prostheses: a review of eight thousand five hundred and seventy-nine primary arthroplasties from the Norwegian Arthroplasty Register. J Bone Joint Surg [Am] 1995;77-A:1543-50.

31. Espehaug B, Furnes 0, Havelin LI, Engesaeter LB, Vollset SE. The type of cement and failure of total hip replacements. J Bone Joint Surg [Br] 2002;84-B:832-8.

32. Furnes 0, Lie SA, Havelin LI, Vollset SE, Engesaeter LB. Exeter and Charnley arthroplasties with Boneloc or high viscosity cement: comparison of 1127 arthroplasties followed for 5 years in the Norwegian Arthroplasty Register. Acta Orthop Scand 1997;68:515-20. 